\title{
Mapping anthropogenic and natural volatile organic compounds around Estarreja Chemical Industrial Complex
}

\author{
T. Nunes, C. Poceiro, M. Evtyugina, M. Duarte, \\ C. Borrego \& M. Lopes \\ CESAM, Centre for Environmental and Marine Studies, \\ Department of Environment and Planning, University of Aveiro, Portugal
}

\begin{abstract}
In the region of Estarreja, since the middle of century XX has settled one of the largest complexes of basic chemical industries in Portugal. During the 80s of the last century, the air quality started to be monitored in this region, but only the classic pollutants were addressed. This region never was submitted to a VOC survey, a group of compounds together $\mathrm{NO}_{\mathrm{x}}$ with a strong impact in ozone production at surface level. Every year ozone exceedances are observed in this region. Adding to this environmental problem, volatile organic compounds include several compounds with negative human health effects, like aromatic compounds. Due to a complexity of sources, industrial, traffic, agriculture and natural, that can drive air quality in the region, field campaigns were planned involving VOCs and $\mathrm{NO}_{2}$ measurements with passive tubes. A set of passive tubes were distributed for 32 sampling locations in an area of $\sim 100 \mathrm{~km}^{2}$. Radiello passive tubes and Palmes type tubes were used for VOCs and $\mathrm{NO}_{2}$ concentration measurements respectively. Four sampling campaigns with a weekly duration were performed between March and June 2012. The values obtained show that toluene was the $\operatorname{VOC}\left(\mathrm{C}_{5}\right.$ to $\left.\mathrm{C}_{12}\right)$, which in general, showed higher concentrations in all campaigns. The highest concentrations of many VOCs like BTEX, and $\mathrm{NO}_{2}$ were observed close to the vicinity of the industrial complex. The high ratio of toluene/benzene pinpoint a heavy influence by emissions from industry, even the ratio of xylene/benzene suggests that this region is also influenced by transport of pollutants from other regions. The high correlations between the xylenes and ethylbenzene in the entire area indicate a single emission source, most likely vehicular emissions, in opposition to what is
\end{abstract}


observed for toluene and benzene. The analysis of the PEC (Propylene Equivalent Concentration) reveals that the biogenic VOCs presents a potential for ozone formation greater than the anthropogenic emissions.

Keywords: air pollution, industrial area, organic volatile compounds (VOCs).

\section{Introduction}

Nowadays, urban air pollution is one of the main challenges to sustainable development in Europe and all over the world. Urban outdoor air pollution is estimated to cause 1.3 million deaths worldwide per year and contributes to $5 \%$ of all cardiopulmonary deaths [1].

In 2001 the European Commission launched the Clean Air for Europe Programme (CAFE) in order to establish a long-term, integrated strategy to tackle air pollution and to protect against its effects on human health and the environment. The CAFE lays the bases for the first of the thematic strategies announced in the Sixth Environmental Action Programme of the European Community entitled "Environment 2010: Our Future, Our Choice" covers the period from 22 July 2002 to 21 July 2012 (COM (2001) 31).

Industrialized areas represent greater concern due to the type of air pollutants and hazards released and additional potential risks of accidents. In order to evaluate the impacts of air pollution on human exposure and health a research project is under development focused in Estarreja case study. This is a growing industrialized urban area located in the central coast of Portugal, with one of the largest chemical industrial complexes in Portugal. The methodology developed has been previous presented by Lopes et al. [1].

Local monitoring air quality data collected on the single measuring station existing in the area showed that the advection of contaminated air masses from neighbour regions and adverse weather conditions associated with local emissions, namely industrial activity and road traffic, are the major contributors to air quality degradation in the study region. Most concerned pollutants are PM10 and tropospheric ozone [2].

However, monitoring data is insufficient for an extended assessment of the impact of the chemical industrial complex on population and individual exposure and for epidemiological studies since volatile organic compounds (VOC) are not measured in this monitoring station. In order to improve the knowledge of VOC distribution patterns in the region, and to assess the influence of the chemical complex, a field campaign to measure was set up covering an extensive area around the chemical complex.

\section{Methodology}

\subsection{Field campaigns}

Sampling campaigns of $\mathrm{NO}_{2}$ and VOCs with passive tubes were carried out in the Estarreja region located at the coastline of Central Portugal (Figure 1). The county of Estarreja has $108 \mathrm{~km}^{2}$ of area and a population density of $261 \mathrm{hab} \mathrm{km}^{2}$. 
This region is characterised by a complexity of natural and anthropogenic sources of air pollutants which includes one of the most important chemical complex, Estarreja Chemical Complex (ECC), representing 20\% of chemical industry in Portugal. Products related with chemical activity include PMDI (methyl diphenyl isocyanate), aniline, polyurethanes, PVC among others.

The most important traffic routes crossing the study area are the highways A1 and A29 and the national road N109. Beyond the high industrial activity and traffic, the agriculture and the cattle breeding are also quite significant in some zones of Estarreja region.

In order to map the VOC patterns in this region 32 sampling locations were distributed in the area of around $100 \mathrm{~km}^{2}$ (Figure 1) and four weekly sampling campaign have been carried out from April to June 2012 with diffusive tubes for $\mathrm{NO}_{2}$ (Palmes type tubes) and VOCs (Radiello diffusive tubes). The sampling locals are identifying in the map and the six colours notation is used to assign the characteristics of each local take into account the type of sources existing in the surroundings: red colour for locals in the vicinity of industrial complex; orange colour for locals close to industry and forest; yellow colour for urban and traffic locals; light blue colour for rural not far from traffic influence; blue colour for forest areas; and dark blue colour for rural places.

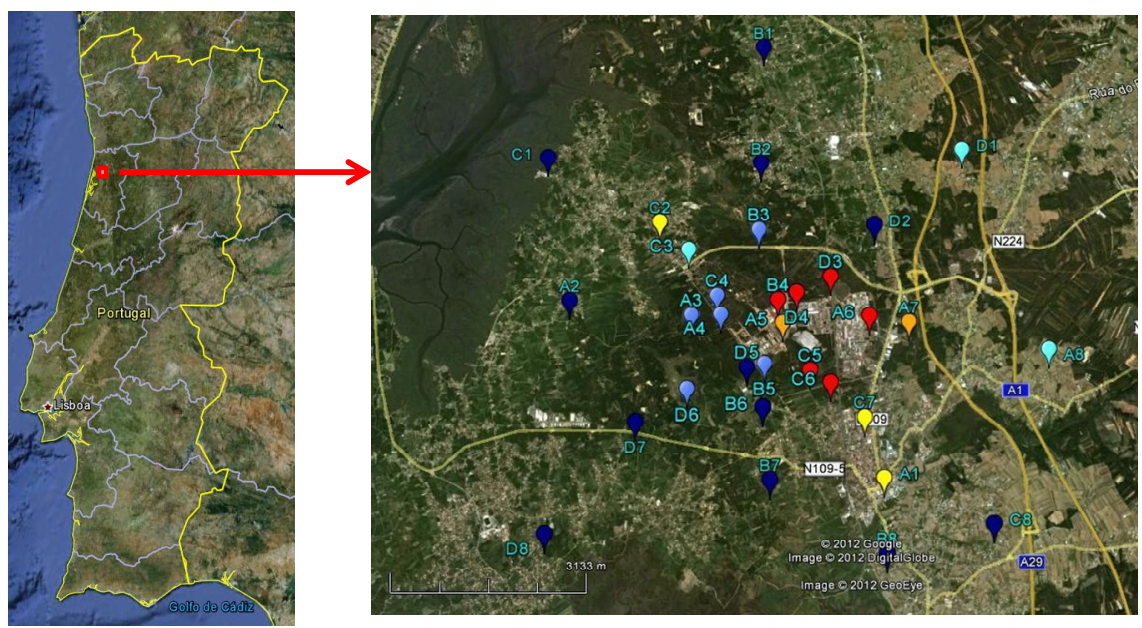

Figure 1: Sampling locations in the Estarreja region.

Meteorological data during each campaign were obtained from the meteorological station at Aveiro University (www.cesam.ua.pt) that is located $15 \mathrm{~km}$ SW away from Estarreja. 


\subsection{Sampling and analysis}

$\mathrm{NO}_{2}$ were sampling with polycarbonate diffusive tubes with steel grids impregnated with triethanolamine that chemiadsorb $\mathrm{NO}_{2}$, as nitrite, which was quantified by visible spectrophotometry [3].

VOCs adsorbed in Radiello tube (chemical desorption) were desorbed and analysed by a thermal desorption/cryogenic concentration method on a Trace Ultra (Thermo scientific) gas chromatograph (GC) equipped with a thermal desorption injector Master TD (DANI) and a flame ionisation detector (FID). VOCs contained in the adsorbent tube were thermally desorbed at $370^{\circ} \mathrm{C}$ with pure helium at 8 psi for $15 \mathrm{~min}$ and cryofocused in a cold trap of the thermal desorber at $-30^{\circ} \mathrm{C}$. The trap was connected to the $\mathrm{GC}$ split/splitless injector by a transfer line heated to $250^{\circ} \mathrm{C}$. Compounds were injected into a column (split flow $35 \mathrm{ml} \mathrm{min}{ }^{-1}$ ) by fast heating of the trap to $250^{\circ} \mathrm{C}$ using helium as a carrier gas (8 psi). A TRB-1MS capillary column $(50 \mathrm{~m} \times 0.20 \mathrm{~mm}$ i.d., $0.50 \mu \mathrm{m})$ was used for separation of VOCs. The $\mathrm{GC}$ oven temperature programme was as follows: $40^{\circ} \mathrm{C}-3 \mathrm{~min}$; from 40 to $160^{\circ} \mathrm{C}$ at $4^{\circ} \mathrm{C} \mathrm{min}{ }^{-1}$; from 160 to $250^{\circ} \mathrm{C}$ at $10^{\circ} \mathrm{C} \mathrm{min}^{-1}$; $270^{\circ} \mathrm{C}-3 \mathrm{~min}$. Before sampling, all tubes were cleaned by regeneration system of the injection unit DANI by passing a stream of pure nitrogen at a flow rate of $10 \mathrm{ml} \mathrm{min}-1$ and temperature of $370^{\circ} \mathrm{C}$ for 30 minutes. The analysis system was carefully calibrated using liquid standards. The detection limit of the technique varied from compound to compound, been in the range of 0.01 to $1.04 \mu \mathrm{g} \mathrm{m}^{-3}$.

\section{Results and discussion}

Although more than 17 different volatile organic compounds $\left(\mathrm{C}_{5}-\mathrm{C}_{12}\right)$ were identified, only compounds with known diffusion rates available in Radiello web page were quantified. However in this communication more attention will be addressed to BTEX (benzene, toluene, ethylbenzene and xylenes) characterization and some VOC from biogenic origin.

Concerning meteorology, during all four field campaigns rain events were registered. From the first to the last campaign $0.4,29,130$ and $30 \mathrm{~mm}$ of precipitation were recorded respectively. The average air temperature range between $12^{\circ} \mathrm{C}$ in the first campaign $\left(6-23^{\circ} \mathrm{C}\right)$ and $18^{\circ} \mathrm{C}$ in the last $\left(12-30^{\circ} \mathrm{C}\right)$, with continues increase from the first to the last one. The wind direction observed during sampling periods is shown in Figure 2. Average wind speed per wind sector was lower than $5.5 \mathrm{~m} \mathrm{~s}^{-1}$, with strongest winds blowing from directions with higher frequency occurrences.

Among the seventeen VOC quantified regularly at each local toluene is always the most abundant compound. Pollutant concentrations varied with local and time. Figure 3 summarizes the VOC concentrations recorded from the four aforementioned compounds in each campaign for the 32 locations in the form of box plot. Only toluene presents the highest average concentration during the first campaign. 

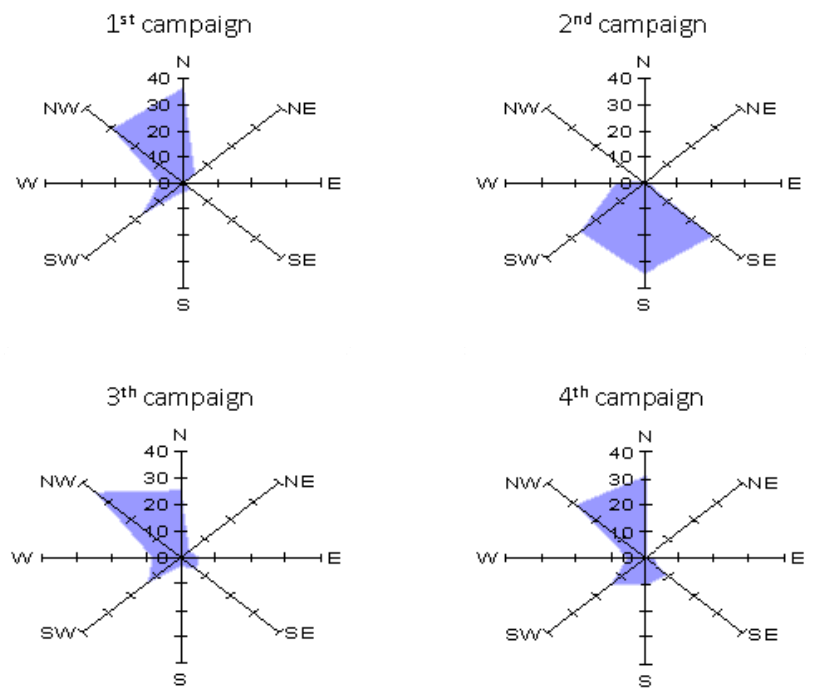

Figure 2: Wind direction frequency observed in each campaign.
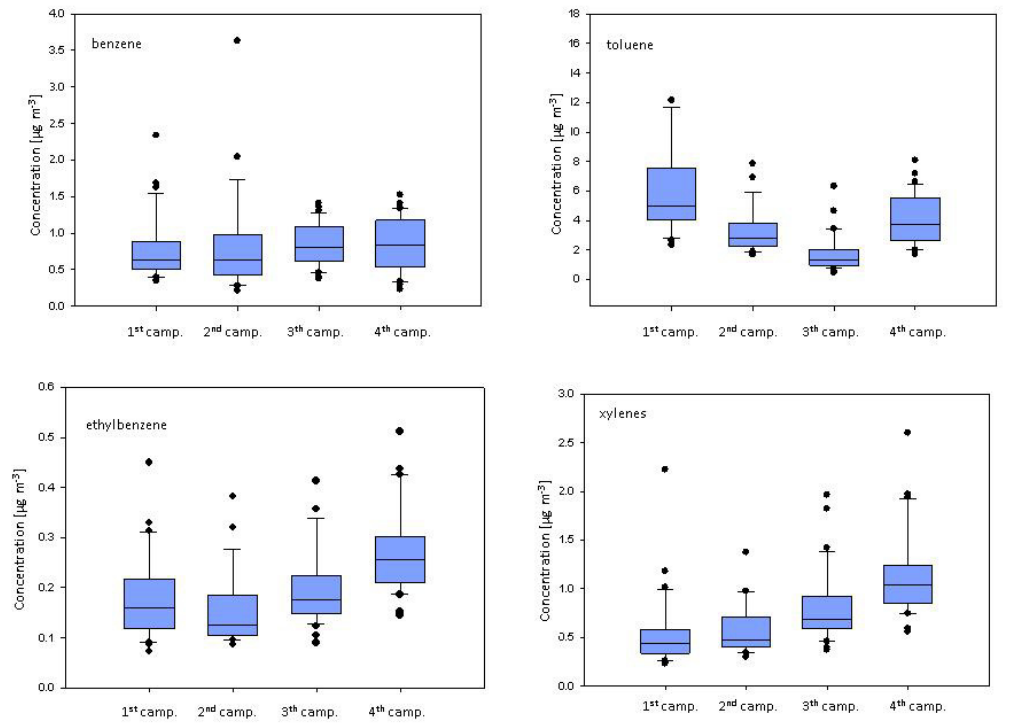

Figure 3: Boxplot of benzene, toluene, ethyl-benzene and xylenes concentrations for each filed campaign. 

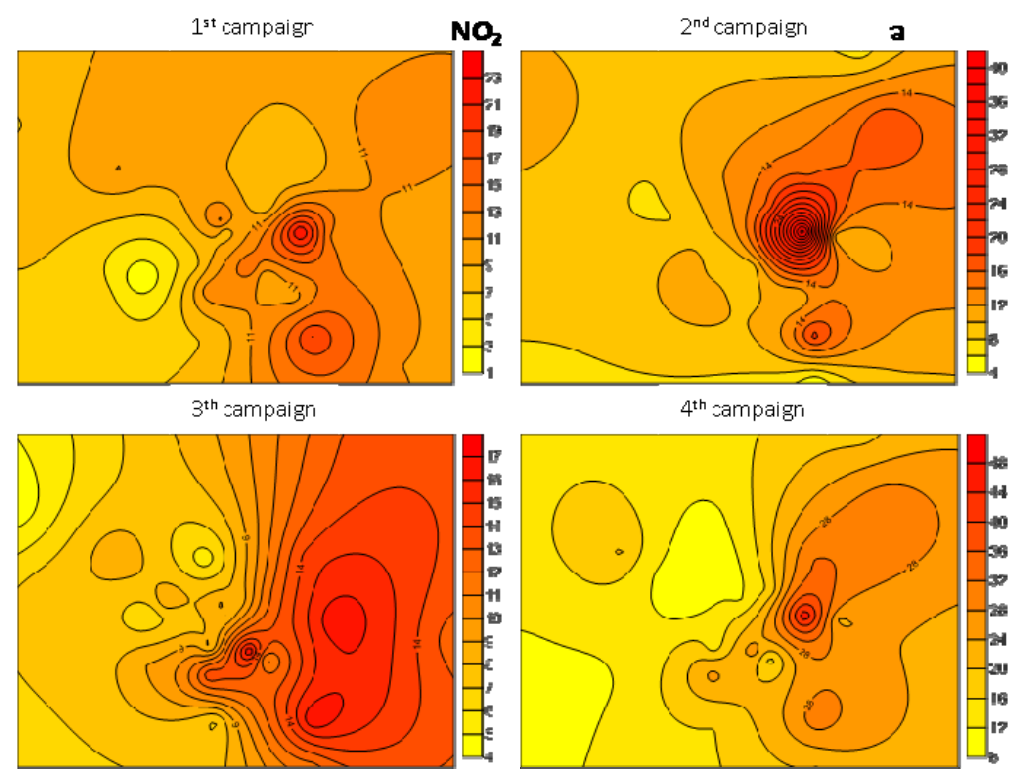

$4^{\text {th }}$ campaigr

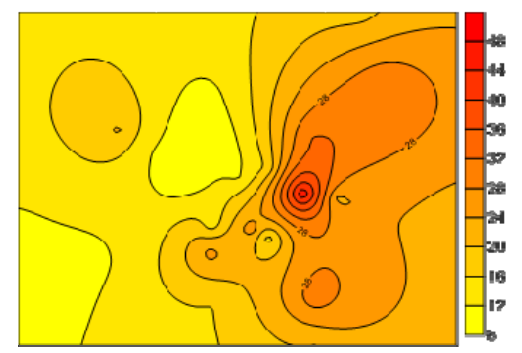

Figure 4: Distribution of $\mathrm{NO}_{2}$ average concentrations $\left(\mu \mathrm{g} \mathrm{m}^{-3}\right)$ over Estarreja region.
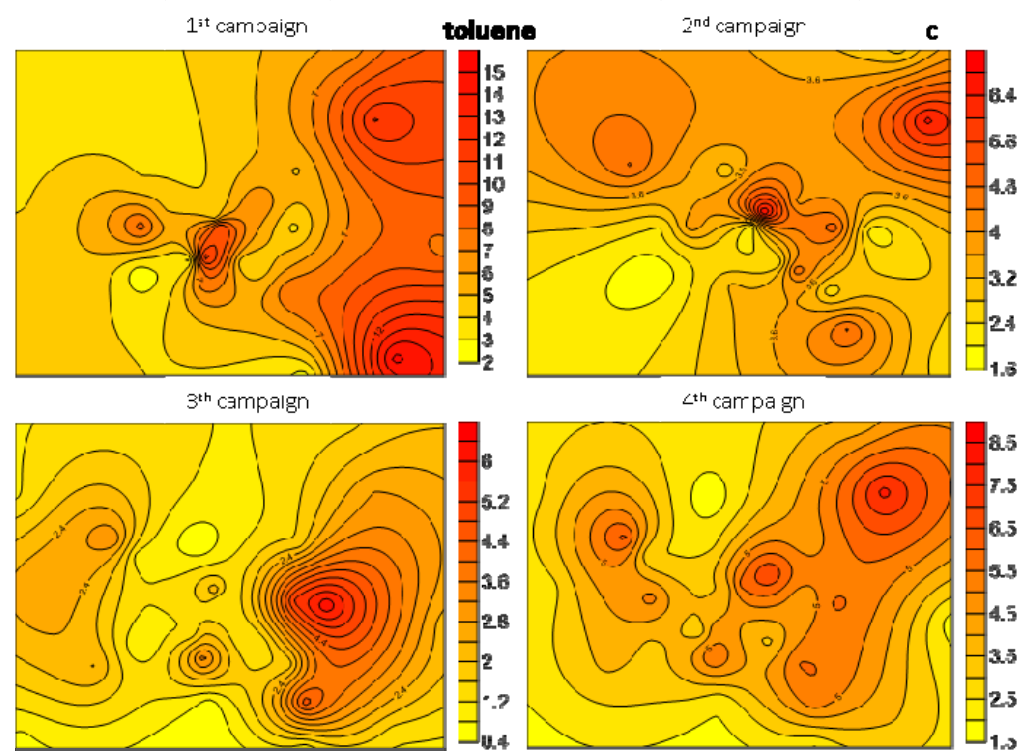

Figure 5: Distribution of toluene average concentrations $\left(\mu \mathrm{g} \mathrm{m}^{-3}\right)$ over Estarreja region. 


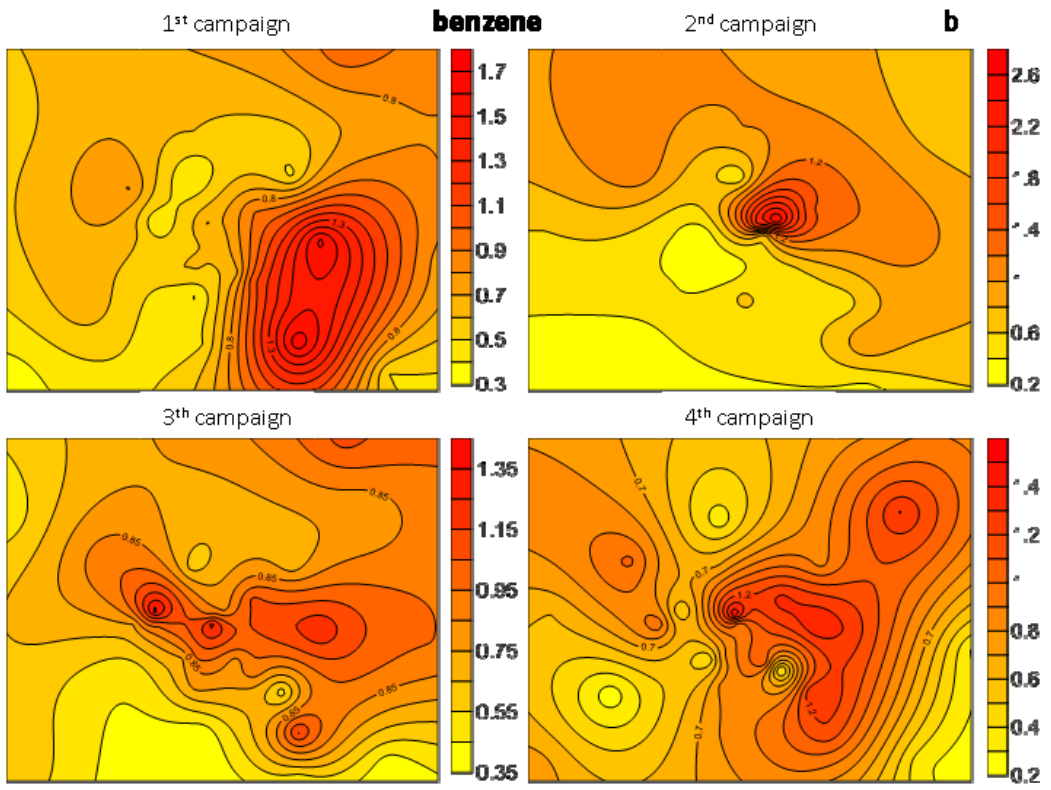

Figure 6: Distribution of benzene average concentrations $\left(\mu \mathrm{g} \mathrm{m}^{-3}\right)$ over Estarreja region.

For a better visualization of air pollutant concentration distribution in the Estarreja region, the Surfer software with krigging interpolation was used. Figures 4, 5 and 6 show the distribution of $\mathrm{NO}_{2}$, benzene and toluene in the Estarreja region at each campaign.

In general the highest average concentrations for the others compounds of the BTEX group and $\mathrm{NO}_{2}$ were observed in the fourth campaign, when warmest temperatures and calm winds were registered. The same behaviour was observed for biogenic terpenic VOC.

Spatial variation of $\mathrm{NO}_{2}$ and aromatic compound concentrations denote the local source emissions influence in the region, industry, traffic and fuelling stations. Two locals close in the vicinity of fuelling stations showed higher concentrations of BTEX than locals with similar characteristics. The transport of pollutants from North (Porto urban area) or South (Aveiro urban area) with significant anthropogenic emissions sources also contributed to the air quality in Estarreja region. Biogenic compounds occurred in fewer concentrations than many anthropogenic VOCs, but due their high reactivity with $\mathrm{OH}$ radical they could have a significant impact on ozone production in the region. During summer ozone exceedances usually are registered in the air quality station of this region $[1,4]$.

In Figure 7, average propylene equivalent concentration (PEC) is plotted for the main biogenic and anthropogenic organic compounds measured during the third and fourth campaign. 
In order to investigate deeply the influence of local and regional emission sources, BTEX ratios were calculated (Table 1 and Figure 8). The ratios between BTEX compounds usual are used for assessing source contribution like traffic and industry.

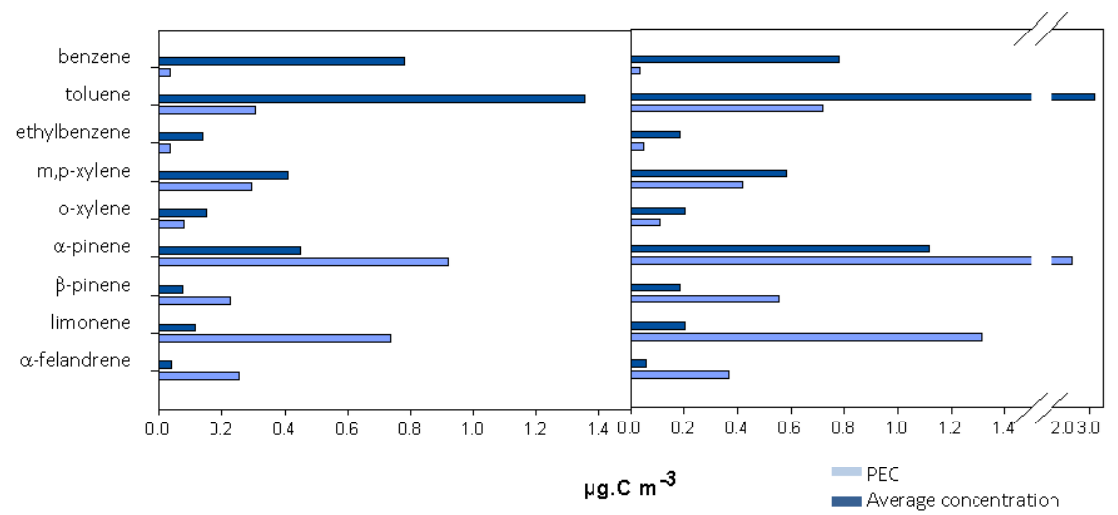

Figure 7: Propylene equivalent concentration and averaged concentration of the most representing VOC during $3^{\text {th }}$ (left) and $4^{\text {th }}$ (right) monitoring campaigns.

Table 1: $\quad$ Linear regression parameters between some of BTEX compounds.

\begin{tabular}{|c|c|c|c|c|}
\hline $\begin{array}{c}\text { Camp } \\
\cdot\end{array}$ & $\begin{array}{c}\text { ethylbnzene vs } \\
\text { xylenes }\end{array}$ & $\begin{array}{c}\text { Ethylbenzene vs } \\
m, p \text {-xylene }\end{array}$ & $\begin{array}{c}\text { ethylbenzene vs } \\
0 \text {-xylene }\end{array}$ & $\begin{array}{c}\text { o-xylene vs } \\
m, p \text {-xylene }\end{array}$ \\
\hline $1^{\text {st }}$ & $y=2.061 x+0.109$ & $y=1.474 x+0.086$ & $y=0.593 x+0.021$ & $y=2.513 x+0.028$ \\
$R^{2}=0.602$ & $R^{2}=0.592$ & $R^{2}=0.613$ & $R^{2}=0.968$ \\
\hline $2^{\text {nd }}$ & $y=3.812 x+0.017$ & $y=2.613 x+0.008$ & $y=1.031 x+0.006$ & $y=2.613 x+0.008$ \\
\hline $3^{\text {th }}$ & $y=4.744 x-0.128$ & $y=3.536 x-0.107$ & $y=1.209 x-0.022$ & $y=2.858 x-0.029$ \\
$R^{2}=0.917$ & $R^{2}=0.974$ & $R^{2}=0.977$ & $R^{2}=0.951$ & $R^{2}=0.981$ \\
\hline $4^{\text {th }}$ & $y=5.160 x-0.251$ & $y=3.805 x-0.186$ & $y=1.355 x-0.066$ & $y=2.771 x+0.010$ \\
& $R^{2}=0.971$ & $R^{2}=0.974$ & $R^{2}=0.957$ & $R^{2}=0.992$ \\
\hline
\end{tabular}

The high correlations between xylenes and ethylbenzene in the studied area with the exception of the first campaign emphasize the recognition of a single area source in the region instead benzene and toluene suffer the contribution of other sources. Toluene/benzene ratios were usual $>3$ excepted in the third campaign. Ratios of toluene/benzene higher than 3 are related with industrial emissions and ratios of 1.5 to 3 are characteristic of traffic emissions [5-9]. However, during all field campaign these two compounds showed a poor 
correlation among them and the same was observed between each one and the others compounds of the BTEX group. The ratios of $(m, p-\mathrm{X} / \mathrm{B})$ and $(o-\mathrm{X} / \mathrm{B})$ exhibit low values, usually lower than 2 , which could be related with the photochemical age of air masses $[10,11]$.
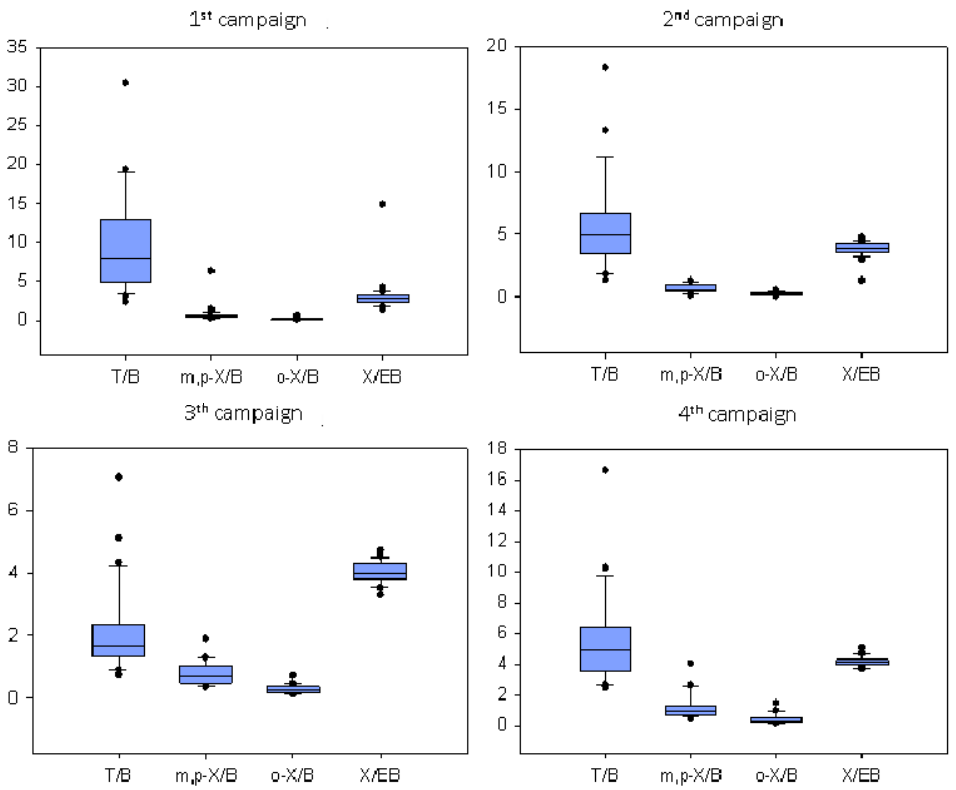

Figure 8: Ratios of BTEX compounds (box-plots) registered in each field campaign.

\section{Conclusions}

The results of the present study shows that the air quality of Estarreja region is significant influenced by Estarreja Chemical Complex even other sources contributed as well for the levels of VOCs and $\mathrm{NO}_{2}$ in the area. Traffic and related sources like fuelling stations are responsible for some concentrations hotspots. The concentrations of BTEX observed are characteristics of urban areas with higher dimension than Estarreja.

The concentration of benzene in some points comes close to the limit value ( $5 \mu \mathrm{g} . \mathrm{m}^{-3}$ for the annual average concentration) fixed for European Union in the Air Quality Framework Directive (Directive 2008/50/CE).

In terms of photochemical production biogenic emissions showed to be a source with higher potential impact than anthropogenic. Further campaigns in summer period and modelling studies will be recommended to a better apportionment of the emission sources impact and to develop better strategies for air quality management in the region. 


\section{Acknowledgement}

The authors wish to thank the Portuguese Science Foundation for the financial support of the Project INSPIRAR (PTDC/AAC-AMB/103895/2008) through FEDER and COMPETE Programmes.

\section{References}

[1] Lopes M., Figueiredo M.L., Monteiro A., Ferreira J., Martins J., Borrego C. (2012) A contribution to air quality management in urban industrializes areas. 20th International Conference on Modelling, Monitoring and Management of Air Pollution. 16-18 May, A Coruña, Espanha.

[2] WHO (2011) Collaboration between the World Health Organization and the National Institute of Environmental Health Sciences: Highlights from 30 years of Partnership. WHO Document Production Services, Geneva, Switzerland.

[3] Brugwang C., Hoareau J., 2003. Variability of $\mathrm{NO}_{2}$ in different environments at a moderately polluted island over the southwestern Indian Ocean. Atmospheric Research 66, 241-259. Chen Y., Bond T.C., 2010. Light absorption by organic carbon from wood combustion. Atmos Chem Phys 10, 1773-1787.

[4] APA, 2005-2011. Environment Institute. QualAr - Base Online on Air Quality, Internet website: http://www.qualar.org

[5] Barleta, B., Meinardi, S., Rowland, F.S., et al. 2005. Volatile organic compounds in 43 Chinese cities. Atmospheric Environment 39, 5979-5990.

[6] Chiang, P.C., Chiang, Y.C., Chang, E.E. \& Chang, S.C. 1996. Characterizations of hazardous air pollutants emitted from motor vehicles. Toxicological and Environmental Chemistry 56, 85-104.

[7] Hoque, R.R., Khillare, P.S., Agarwal, T., Shkidhar, V. \& Balachandran, S. 2008. Spatial and temporal variation of BTEX in the urban atmosphere of Delhi, India. Science of the Total Environment 392, 30-40.

[8] Khoder, M.I. 2007. Ambient levels of volatile organic compounds in the atmosphere of Greater Cairo. Atmospheric Environment 41, 554-566.

[9] Liu, J., Mu, Y., Zhang, Y., et al., 2009. Atmospheric levels of BTEX compounds during the 2008 Olympic Games in the urban area of Beijing. Science of the Total Environment 408, 109-116.

[10] Zhang, J., Wang, T., Chameides, W.L., Cardelino, C., Blake, D.R., Streets, D.G., 2008. Source characteristics of volatile organic compounds during high ozone episodes in Hong Kong, southern China. Atmospheric Chemistry and Physics 8, 4983-4996.

[11] Nelson, P.F., Quigley, S.M., 1983. The m,p-xylenes:ethylbenzene ratio. A technique for estimating hydrocarbon age in ambient atmospheres. Atmospheric Environment 17, 659-662. 